\title{
Multicomponent cognitive-behavioral therapy for intermittent explosive disorder by videoconferencing: a case study
}

\author{
Jorge Osma ${ }^{1 *}$, Elena Crespo ${ }^{2,3}$ y Cristian Castellano ${ }^{2}$ \\ 1 Universidad de Zaragoza (Spain). \\ 2 Universitat Jaume I \& 3 CREOS, centro de psicoterapia y formación (Castellón, Spain).
}

\begin{abstract}
Título: Terapia Cognitivo-Conductual multicomponente para el tratamiento del Trastorno Explosivo Intermitente por videoconferencia: un estudio de caso.

Resumen: La Terapia Cognitivo-Conductual (TCC) para el tratamiento del Trastorno Explosivo Intermitente (TEI) ha probado ser eficaz, con tamaños del efecto de moderados a altos, tanto en intervenciones individuales como grupales. La videoconferencia ha sido utilizada eficazmente para tratar distintos trastornos mentales, pero su utilización en pacientes con TEI es todavía desconocida. El objetivo de este estudio es ofrecer evidencias preliminares sobre la posibilidad de tratar el TEI a través de videoconferencia. Presentamos un experimento de estudio de caso de un varón español, de 33 años de edad, que vive y trabaja en China. Después de la intervención, los episodios agresivos del paciente disminuyeron de manera importante así como el afecto negativo. Por otro lado, el paciente mostró un importante incremento en emociones positivas y autoestima. Se produjeron también cambios positivos en algunas dimensiones de personalidad y sus facetas, evaluadas con el NEO-PI-R, específicamente en neuroticismo, extraversión y amabilidad. Los beneficios se mantuvieron en los seguimientos a los 3,8 y 18 meses. Estos resultados preliminares revelan que la TCC por videoconferencia, orientada al incremento de las habilidades en regulación emocional, fue eficaz en un estudio de caso con TEI.

Palabras clave: terapia por videoconferencia; terapia cognitivoconductual; trastorno explosivo intermitente; regulación emocional; NEO-
\end{abstract} PI-R; Skype; estudio de caso.

\section{Introduction}

According to the Diagnostic and Statistical Manual of Mental Disorders, fifth edition (DSM-5; American Psychiatric Association [APA], 2013), Intermittent Explosive Disorder (IED) is classified within the "disruptive, impulse-control, and conduct disorders" chapter. People with IED diagnosis have recurrent behavioral outbursts representing a failure to control aggressive impulses manifested by verbal or physical aggression toward property, animals, or other individuals. According to DSM-5 (APA, 2013) criteria, the core feature of IED is failure to control impulsive aggressive behavior in response to subjectively experienced provocation (i.e., psychosocial stressors) that would not typically result in an aggressive outburst. The aggressive outbursts are generally impulsive and/or anger-based, rather than premeditated or instrumental and are associated with significant distress or impairment in psychosocial function. The symptoms often appear and resolve in minutes to hours, and the person feels a sense of remorse after the episodes.

* Dirección para correspondencia [Correspondence address]: Jorge Osma, Ph. D., Facultad de Ciencias Sociales y Humanas. Universidad de Zaragoza. C/ Ciudad Escolar s/n 44003 Teruel (Spain). E-mail: osma@unizar.es
Abstract: Cognitive-behavioral Therapy (CBT) for the treatment of Intermittent Explosive Disorder (IED) has proved to be effective, with moderate to large effect sizes both in individual and group interventions. Videoconferencing has been used effectively to treat different mental disorders but its use for IED patients is as yet unknown. The aim of this study is to provide preliminary evidence of the possibility of treating IED by videoconference. We present a case-study experiment of a Spanish male, aged 33 years, living and working in China. After the intervention, the patient's aggressive episodes decreased dramatically, as well as his negative affect. In contrast, he showed an important increment in positive emotions and self-esteem. There were also positive changes in some personality dimensions and facets measured by NEO-PI-R, specifically in neuroticism, extraversion, and agreeableness. The benefits were maintained at 3-, 8- and 18-month follow-ups. These preliminary results reveal that CBT by videoconference oriented to increasing emotion regulation skills was effective when implemented in a case study of a person suffering from IED.

Key words: videoconference therapy; cognitive-behavioral therapy; intermittent explosive disorder; emotional regulation; NEO-PI-R; Skype; casestudy.

The etiology of IED is unclear but it usually begins in late childhood or adolescence and rarely after age of 40 (mean age at onset is 14 years). No sex differences have been found, it is quite persistent over the life course, and is associated with substantial role impairment (APA, 2013; Coccaro, 2012; Kessler et al., 2006; McCloskey, Noblett, Deffenbacher, Gollan, \& Coccaro, 2008). It has high comorbidity with other mood, anxiety, and substance use disorders (APA, 2013; McCloskey et al., 2008). In addition, IED is a much more common condition than previously recognized; lifetime prevalence is 5.4 to $7.3 \%$ and 12 -month prevalence 2.7 to $3.9 \%$ (APA, 2013; Kessler et al., 2006).

Some studies have indicated that pharmacological treatments, such as lithium, valproic acid, carbamazepine, phenytoin, fluoxetine, or atypical antipsychotics are more effective than placebo in treating aggression (Blankenship, 2008). With respect to nonpharmacological therapy, there are few studies evaluating treatment for IED (Olvera, 2002). The metaanalytic reviews of anger treatments support the conclusion that cognitive-behavioral therapies (CBT) show a moderate to large effect for anger and aggression at the end of treatment, with similar effects at follow-up (Blankenship, 2008; McCloskey et al., 2008). In this sense, multicomponent treatments containing both cognitive and behavioral components receive the most empirical support (Del Vecchio \& O'Leary, 2004). More recently, a study supported the effica- 
cy of multicomponent CBT therapy (MCBT) (including cognitive restructuring, relaxation, and coping skills training) in the treatment of IED (McCloskey et al., 2008).

Several controlled studies have been conducted exploring the efficacy of Information and Communication Technologies (ICTs) in psychological interventions, for both the prevention and treatment of mental disorders such as anxiety (Proudfoot, et al., 2003), bipolar disorder (Proudfoot, Parker, Benoit, Manicavasagar, \& Smith, 2007), depression (Anderson et al., 2005), social phobia (Anderson et al., 2006), panic disorder (Villa, Botella, García-Palacios, \& Osma, 2007), fear of flying (Botella, Osma, García-Palacios, Quero, \& Baños, 2004), complicated grief (Botella, Osma, García-Palacios, Guillén, \& Baños, 2008), body image disturbance (Marco, Perpiñá, \& Botella), and the promotion of healthy behaviors such as alcohol use control (Walters, Miller, \& Chiauzzi, 2005), physical activity (Spittaels, \& De Bourdeaudhuij, 2006), or smoking cessation (Walters, Wright, \& Shegog, 2006), among many others. These studies have been carried out with different ICTs, such as virtual or augmented reality or Internet-based psychological treatments (for a review, see Peñate, 2012). Another ICT that seems useful for psychological assessment and treatment could be videoconferencing.

Videoconference occurs simultaneously between therapist and patient and is very similar to face-to-face intervention. According to different authors, there are several advantages of videoconferencing therapy: patients do not have to travel to and from a provider's office, greater continuity of care, lower costs, access to isolated and/or stigmatized groups, possibility of relapse prevention, the patient is able to control the intervention, it is possible to enhance the structure of the intervention program, it allows the exchange of nonverbal communication between therapist and patient, and the use of a tool (the Internet) that is attractive to young people and to professionals (Soto-Pérez, Franco, Monardes, \& Jiménez, 2010).

Videoconferencing has been used effectively to treat different mental disorders (Simpson, 2009; Vogel et al., 2014). Despite the increasing scientific evidence of the effectiveness of this type of therapy, its dissemination is not as prolific as might be expected. This could be attributed mainly to two biases widely shared by therapists. The first refers to the lack of users and therapists' mastery of ICT, and the second one to the idea of a limited bond between therapist and patient, which could negatively affect the interpersonal contact. In this regard, some studies indicate that the level of expertise with ICT does not correlate with the improvement obtained (Soto-Pérez et al., 2010; Yuen, Goetter, Herbert, \& Forman, 2012). Moreover, the anonymity and privacy that characterizes videoconferencing therapy seems to promote sincerity and lack of inhibition in the therapeutic relationship, given that no significant differences were obtained between videoconferencing and face-to-face therapy (Knaevelsrud \& Maercker, 2007). In this regard, the recent review conducted by Simpson and Reid (2014) concluded that therapeutic alliance can be developed in psychotherapy by videoconference, with clients rating bond and presence at least as strongly as face-to-face settings across a range of diagnostic groups. Furthermore, there are also studies reporting high satisfaction with videoconferencing therapy by therapists and patients (Simpson, 2009).

One of the videoconferencing systems that have been used successfully to offer therapy interventions is Skype (i.e., Goetter, Herbert, Forman, Yuen, \& Thomas, 2014; Yuen et al., 2013). Skype is a free or cheap system that offers, among other services, the possibility of communicating in real time, and it is easy to download and use. Some investigations in Internet-Mediated Telemental Health have indicated that, although Skype employs peer-to-peer communications and encryption technology, the security of these messages cannot be one hundred percent guaranteed. In order to reduce the negative characteristics of the Skype System in this field, they recommended patients be informed of the privacy risks associated with videoconferencing communication, as well as of the user policies of the videoconferencing service with regards to the collection of personal information (Yuen et al., 2012; Yuen et al., 2013).

To our knowledge, there are no published studies on videoconferencing therapy specifically for the treatment of IED. We expected that an MCBT administered by videoconferencing would be efficacious to increase the emotion regulation in the case of a Spanish patient diagnosed with IED who was living in China.

\section{Method}

\section{Participant}

The patient was a 33-year-old male Spaniard, living in China with his partner and who had been working in his own company for three years. He worked in different companies until he decided to start his own project in China. He had not received any previous psychological or pharmacological treatment but remembers having experienced such aggressive episodes in childhood and adolescence when things did not go as he wished. He also says that, "I have always got what I wanted easily." The patient requests psychological help during his holidays in Spain at CREOS, centro de psicoterapia y formación, because the frequency of the aggressive episodes had increased in recent months, and it was very difficult for him to control them.

\section{Measures}

Before beginning the assessment process, the patient signed the confidentiality and informed consent document, which included the special characteristics and conditions of the psychological intervention program by videoconference (i.e., place to conduct the online therapeutic appointments, the use of email to send and receive material, or the payment terms of the sessions). 


\section{Third-person reports}

Three videoconferences and five e-mails were exchanged with the patient's partner during the assessment and treatment period. The purpose was to obtain more information about the patient's everyday life, about how she describes and experiences the aggressive episodes, and which objectives she thinks her partner should achieve with the psychological treatment. In the assessment period, she expressed her main complaints about her partner: his lack of selfcontrol, his insistence on doing things his way, the fact that he does not listen to her, he misinterprets her, his lack of empathy and generosity, his passive attitude when he says, "I am no good at this, do it yourself!", and his impulsive decision-making.

\section{Primary outcome measures}

The primary outcome measures were the clinical improvement of the aggressive episodes, anxiety and depressive symptoms, and the personality dimension of Neuroticism and all its facets.

Emotional self-record (Linehan, 1993). We used the emotional self-record designed by Marsha M. Linehan (1993) to assess the aggressive episodes over time. This emotional self-record provides valuable information about the number of episodes and triggering stimuli, the patient's emotional response, and the consequences of his or her reactions. In addition, this self-record can be also used as an aid in the functional analysis and problem-solving training techniques.

State-Trait Anxiety Inventory (STAI; Spielberger, Gorsuch, \& Lushene, 1970, Spanish adaptation by GuillénRiquelme \& Buela-Casal, 2011). The STAI is a self-report measure, comprising two 20 -item scales that assess state and trait levels of anxiety. We used the Trait subscale, in which respondents indicate how they generally feel on a four-point Likert-type scale ranging from 0 (never) to 3 (always). The items of the Trait Scale presented a Cronbach alpha of .90 for the Spanish adaptation, showing an adequate internal consistency.

Beck Depression Inventory (BDI-II; Beck, Steer, \& Brown, 1996, Spanish adaptation by Sanz, Navarro, \& Vázquez, 2003). This instrument comprises 21 items assessing the intensity of depression. In each of the items, subjects choose the words from a set of four alternatives ( 0 to 3 points), always ordered by their severity, that best describe their average state during the past week, including the day of the measurement. The total score ranges from 0 to 63 . The questionnaire presented a Cronbach alpha of .83 and testretest reliability of .72 for a 1 -month interval. It has also performed well regarding content validity, and convergent and discriminant validity, showing good psychometric properties as an assessment tool of the depressive syndrome.

Revised NEO Personality Inventory (NEO-PI-R; Costa \& McCrae, 1992, adapted for Spanish population by Cordero, Pamos, \& Seisdedos, 2008). This inventory assesses personality from a dimensional approach with 240 items. Respondents rate the inventory items on a 5 -point scale ranging from 1 (strongly disagree) to 5 (strongly agree). The NEO-PI-R provides a personality profile based on the five basic dimensions (Neuroticism, Extraversion, Openness, Agreeableness, and Conscientiousness) and their facets. Regarding reliability, alpha coefficients between .86 and .92 were obtained; testretest reliability was also adequate, and the facets show indices ranging between .69 and .92, and between .86 and .91 in the dimensions. The NEO-PI-R has good construct, convergent, and discriminant validity.

\section{Secondary outcome measures}

Anxiety Sensitivity Index (ASI; Reiss, Peterson, Gursky, \& McNally, 1986, Spanish adaptation by Sandin, Chorot, \& McNally, 2001). The ASI questionnaire contains 16 items that measure the fear of anxiety symptoms that a person may experience. Each item is scored on a 5-point scale ranging from 0 (not at all) to 4 (very much). The total score ranges from 0-64; higher scores indicate higher levels of anxiety sensitivity. There is evidence of the reliability and validity of the ASI (Peterson \& Reiss, 1993).

Positive and Negative Affect Schedule (PANAS; Watson, Clark, \& Tellegen, 1988, Spanish adaptation by Sandin et al., 1999). The 20-item PANAS comprises two mood scales, one measuring positive affect and the other measuring negative affect. Each item is rated on a 5 -point scale ranging from 1 (very slightly or not at all) to 5 (extremely), indicating the extent to which the respondent has felt this way in the specified time frame. The reported Cronbach alpha coefficients for various reference time intervals ranging from .86 to .90 for the Positive Affect Scale and from .84 to .87 for the Negative Affect Scale. Test-retest correlations for an 8 -week period ranged from .47 to .68 for Positive Affect and from .39 to .71 for Negative Affect.

The Rosenberg Self-Esteem Scale (RSE; Rosenberg, 1989, Spanish adaptation by Vázquez, Jiménez, \& Vázquez, 2004). This 10-item Likert-type scale is rated on a 4-point scale (from strongly agree to strongly disagree). The scale measures state self-esteem by asking the respondents to reflect on their current feelings. The Spanish version has high internal consistency (Cronbach's alpha between .80 and .87) and testretest reliability of .72 .

Client Satisfaction Questionnaire (CSQ-8; Roberts, Atkinson, \& Mendias, 1984). The CSQ-8 is an 8-item measure that is used to assess the client's satisfaction with the services provided. This questionnaire yields a global measure of the client's perception of the general value of the services (psychological intervention). Scores range from 8 to 32, with higher scores indicating greater satisfaction. It has been reported to have internal consistency, with Cronbach alpha scores ranging from .86 to .94 . 


\section{DSM-IV-TR Multiaxial diagnostic interview}

A non-structured diagnostic interview was carried out using DSM-IV-TR (American Psychiatric Association [APA], 2000) criteria for Axis I and II, because the DSM-5 version had not yet been published. The following multiaxial diagnosis was reached: Axis I: IED (F63.81); Axis II: no diagnosis of personality disorder, but very high neuroticism; Axis III: no disease; Axis IV: very low assertiveness, relationship and occupational problems; and Axis V (Global Assessment Functioning): score of 45, implying serious impairment in personal life, occupational functioning, and relationships. The IED symptoms were not accounted for by substance intake or medical conditions. Given the nature of IED, differential diagnosis was carried out with mood or anxiety disorders-specifically, bipolar disorder-substance abuse or dependence, and personality disorder-specifically, borderline, antisocial, and histrionic personality disorders. The patient did not meet the DSM-IV-TR diagnostic criteria for any of these mental disorders.

\section{Procedure and MCBT program by videoconference}

The complete therapeutic program was implemented in 20 sessions over 34 weeks of intervention. The first 3 sessions were dedicated to face-to-face assessment (60-90 minutes weekly sessions); the patient took vacation time in Spain for the assessment sessions and then returned to China. The remaining 17 sessions were devoted to treatment intervention by videoconference (60-75 minutes) with the Skype system. The first 8 sessions were conducted onceweekly, 6 more sessions once every two weeks, and the last 3 sessions were conducted every three weeks. The therapeutic components and techniques selected were: 1) Reducing physiological arousal (3 sessions) by training progressive muscle relaxation, deep breathing, and some common Chinese relaxing activities (e.g., head massage); 2) Cognitivebehavior therapy and increasing resources to cope with stress (10 sessions) through emotional education, functional analysis of the aggressive episodes, stimulus control (i.e., time out), cognitive restructuring, exposure to emotions and situations, and assertiveness and problem-solving training; 3) Increasing the experience of positive emotions ( 3 sessions) through scheduling pleasant activities, evaluation and practice of personal strengths, exercises based on positive psychology such as promoting laughter, helping others, or expressing gratitude; and, lastly, 4) Relapse prevention (1 session) through recognizing the variables that can negatively influence emotional balance, facing the future with realism and hope, what to do if he has a relapse, and holistic health as a lifetime learning process.
Between sessions, the patient sent the tasks he was asked to perform by email (i.e., emotional self-records, exposure exercise records). When the treatment was completed, follow-up sessions were established at 3, 8, and 18 months (depending on his availability). These follow-ups were conducted entirely by videoconferencing. The whole process was applied by a psychologist with 12 years of experience in CBT for emotional disorders and in the application of ICT for psychological assessment and treatment (first author).

\section{Data Analysis}

C statistical analysis was used to obtain quantitative information on trends for aggressive episodes during the baseline period and to evaluate the effects of the MCBT. Figure 1 illustrates the statistical results in a graph, the most common method to view the effect of treatment in single-case studies. For the rest of the measures, we used descriptive data of the results and calculated the percentage of change from pretest period. Finally, to better understand the qualitative data of the case study, we performed a functional analysis of the patient's emotional experiences. We also collected the opinions of the therapist and the patient about the advantages and disadvantages of using videoconferencing.

\section{Results}

\section{Primary Outcomes}

The self-record used in this case provided important clinical information and allowed the functional analysis of the patient's aggressive episodes (see Table 1).

Figure 1 shows a progressive reduction in the aggressive episodes throughout the intervention program and followups (see Table 2). The only aggressive episode recorded between the first and second follow-up assessment was due to the separation process from his partner.

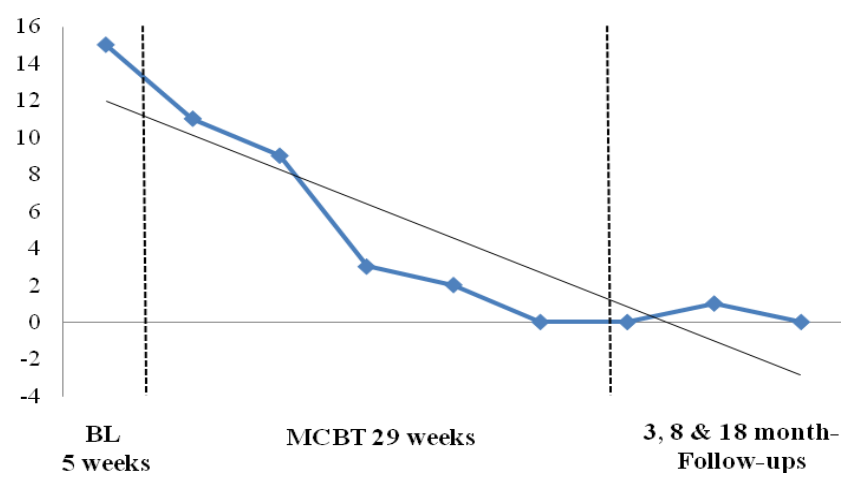

Figure 1. Number of aggressive episodes during the baseline (BL), Multicomponent Cognitive-Behavioral Therapy (MCBT), and follow-ups. 
Table 1. Functional analysis of patient's emotional experiences.

\begin{tabular}{|c|c|c|}
\hline Antecedents & Responses & Consequences \\
\hline $\begin{array}{l}\text { Work-related } \\
\text { Conflicts with colleagues, starting a new } \\
\text { business project in China with high economic } \\
\text { pressure, not achieving goals or receiving } \\
\text { negative criticism. } \\
\text { Family-related } \\
\text { The continuing demand by his mother to re- } \\
\text { turn to Spain or being misunderstood. } \\
\text { Partner-related } \\
\text { Arguing, receiving negative criticism, working } \\
\text { together or her not doing what he wanted to } \\
\text { do. } \\
\text { Emotion-related } \\
\text { Feelings of anger, sadness, fear or insecurity. }\end{array}$ & $\begin{array}{l}\text { Cognitive } \\
\text { Thoughts about inability, uncertainty, loss of con- } \\
\text { ctrol, being misunderstood, everything will go } \\
\text { wrong, nobody loves him or people do not trust } \\
\text { him. } \\
\text { Physiological } \\
\text { Feelings of warmth, flushing, muscle tension, } \\
\text { sweating, tachycardia, breathlesness or sleep prob- } \\
\text { lems. } \\
\text { gBehavioral } \\
\text { Running away from places, jumping, screaming, } \\
\text { scratching own face, writing on the floor, tearing } \\
\text { his clothes and undressing, throwing or hitting ob- } \\
\text { jects, or drinking alcohol. } \\
\text { Emotional } \\
\text { Anticipatory anxiety, hypervigilance towards physi- } \\
\text { ological responses, sadness and hopelessness, inse- } \\
\text { curity and aggressive attitude. }\end{array}$ & $\begin{array}{l}\text { After aggressive episodes, he receives at- } \\
\text { tention and care from his partner, family } \\
\text { and friends. } \\
\text { Avoiding talking about his thoughts and } \\
\text { feelings. } \\
\text { Avoiding negative thoughts and past } \\
\text { memories related to aggressive episodes. } \\
\text { Sometimes he avoids making decisions } \\
\text { and solving problems. } \\
\text { Sometimes his partner and colleagues do } \\
\text { not express their disagreement with him. } \\
\text { Avoiding talking to his mother. } \\
\text { Sometimes he reduces his activity and } \\
\text { adopts a passive attitude or increases his } \\
\text { social activity in order to avoid feelings of } \\
\text { sadness and fear. }\end{array}$ \\
\hline
\end{tabular}

Table 2. C-Statistic results for aggressive episodes during baseline, MCBT, and follow-ups.

\begin{tabular}{|c|c|c|c|}
\hline Assessment periods and therapeutic techniques & C-Statistic & Trend & Direction \\
\hline \multirow[t]{2}{*}{5 weeks BL } & -.04 & Horizontally stable & - \\
\hline & $\begin{array}{c}\text { C-Statistic } \\
\text { BL }\end{array}$ & & \\
\hline Emotional education \& relaxation & $.63^{* *}$ & Trend evident & Positive \\
\hline Functional analysis \& stimulus control & $.73^{* *}$ & Trend evident & Positive \\
\hline Cognitive restructuring, emotion regulation, \& exposure & $.78^{* *}$ & Trend evident & Positive \\
\hline Assertiveness \& problem-solving training & $.82 * *$ & Trend evident & Positive \\
\hline Positive Psychology & $.83^{* *}$ & Trend evident & Positive \\
\hline 3-month follow-up & $.82 * *$ & Trend evident & Positive \\
\hline 8-month follow-up & $.81^{* *}$ & Trend evident & Positive \\
\hline 18-month follow-up & $.82^{* *}$ & Trend evident & Positive \\
\hline
\end{tabular}

Note: MCBT: Multicomponent Cognitive Behavioral Therapy; BL: Baseline; Trend in the positive direction: change toward improved outcome. $* * p<.01$.

Regarding the anxiety and depression outcome, Table 3 shows that the pre-treatment STAI-T scores were very high in comparison with the normative data. After treatment and in all the follow-up periods, the scores were below the average normative data. The pre-treatment DBI-II score corresponds to a moderate depression, whereas after treatment and in all the follow-up periods, the scores were equivalent to no depression.

The patient's pre-treatment personality profile, considering only the Big-Five factors, was characterized by high Neuroticism, low Extraversion, average Openness, and low Agreeableness and Conscientiousness. The post-treatment personality profile was characterized by average Neuroticism, high Extraversion, high Openness, average Agreeableness, and low Conscientiousness. At the last follow-up, 18 months after completing the treatment, the only changes from the posttest period were in Extraversion (reaching an average level) and Openness to experience (reaching a very high level). Regarding the personality facets, we highlight the results obtained in the Neuroticism, Extraversion, and Agreeableness facets. All the Neuroticism facet scores were reduced after treatment and were maintained until the last follow-up, except for the impulsivity facet. With regard to the Extraversion, Openness to experience, and Agreeableness facet scores, the majority of them increased after treatment and were maintained until the last follow-up, except for activity and excitement seeking (Extraversion), actions (Openness to experience), and modesty (Agreeableness). Finally, Conscientiousness facet scores remained unchanged after treatment and in the subsequent follow-ups, but self-discipline was higher and achievement striving was lower.

\section{Secondary Outcomes}

As shown in Table 3, the post-treatment scores in the ASI and PANAS (negative affect) sank below average normative data and were maintained at the follow-ups. The patient also showed a significant increase in positive emotions (Positive Affect Scale) and self-esteem (RSE) after treatment, and progressive increases at the follow-up periods. Finally, the patient rated his satisfaction with videoconference therapy as excellent (28 total score in CSQ-8). 
Table 5 shows the therapist and patient results with reference ing treatment format. to the advantages and disadvantages of the videoconferenc-

Table 3. Normative data, clinical measures scores, and percentage of change obtained at pretest, posttest, and follow-up periods.

\begin{tabular}{lcccccc}
\hline & $\begin{array}{c}\text { Normative data } \\
M(S D)\end{array}$ & Pretest & $\begin{array}{c}\text { Posttest } \\
(\% \mathrm{PCP})\end{array}$ & $\begin{array}{c}3-\mathrm{MFU} \\
(\% \mathrm{PCP})\end{array}$ & $\begin{array}{c}8-\mathrm{MFU} \\
(\% \mathrm{PCP})\end{array}$ & $\begin{array}{c}18-\mathrm{MFU} \\
(\% \mathrm{PCP})\end{array}$ \\
\hline ASI & $18.2(9.1)$ & 28 & $10(-64.28)$ & $11(-60.71)$ & $8(-71.43)$ & $8(-71.43)$ \\
BDI-II & $9.2(7.5)$ & 19 & $6(-68.42)$ & $2(-89.47)$ & $1(-94.74)$ & $0(-100.00)$ \\
PANAS+ & $33.9(8.4)$ & 23 & $39(69.56)$ & $38(65.22)$ & $40(73.91)$ & $45(95.65)$ \\
PANAS- & $18.7(6.8)$ & 40 & $17(-57.5)$ & $19(-52.50)$ & $23(-42.50)$ & $16(-60.00)$ \\
STAI-T & $18.9(10.0)$ & 48 & $14(-70.83)$ & $15(-68.75)$ & $17(-64.58)$ & $15(-68.75)$ \\
RSQ & $31.5(4.5)$ & 28 & $37(32.14)$ & $35(25.00)$ & $35(25.00)$ & $36(28.57)$ \\
\hline
\end{tabular}

M: Mean; SD: Standard Deviation; \%PCP: Percentage of change from pretest; MFU: Month Follow-up; ASI: Anxiety Sensitivity Index; BDI-II: Beck Depression Inventory-II; PANAS +: Positive and Negative Affect Schedule-Positive Scale; PANAS-: Positive and Negative Affect Schedule-Negative Scale; STAI-T: State-Trait Anxiety Inventory- Trait Scale; RSQ: Rosenberg Self-esteem Questionnaire.

Table 4. Pretest, posttest, and follow-up personality dimensions and facet scores measured by NEO-PI-R.

\begin{tabular}{|c|c|c|c|c|c|}
\hline & Pretest & $\begin{array}{l}\text { Posttest } \\
(\% \mathrm{PCP})\end{array}$ & $\begin{array}{c}3 \mathrm{MFU} \\
(\% \mathrm{PCP})\end{array}$ & $\begin{array}{c}8 \mathrm{MFU} \\
(\% \mathrm{PCP})\end{array}$ & $\begin{array}{l}18 \mathrm{MFU} \\
(\% \mathrm{PCP})\end{array}$ \\
\hline Neuroticism & 71 & $49(-30.98)$ & $51(-28.17)$ & $53(-25.35)$ & $50(-29.58)$ \\
\hline Anxiety & 69 & $43(-37.68)$ & $46(-33.33)$ & $46(-33.33)$ & $43(-37.68)$ \\
\hline Angry Hostility & 68 & $56(-17.65)$ & $46(-32.35)$ & $46(-32.35)$ & $50(-26.47)$ \\
\hline Depression & 66 & $43(-34.85)$ & $50(-24.24)$ & $56(-15.15)$ & $54(-18.18)$ \\
\hline Self-Consciousness & 66 & $34(-48.48)$ & $49(-25.76)$ & $40(-39.39)$ & $37(-43.94)$ \\
\hline Impulsiveness & 73 & $63(-13.70)$ & $66(-9.59)$ & $71(-2.74)$ & $69(-5.48)$ \\
\hline Vulnerability & 71 & $53(-25.35)$ & $53(-25.35)$ & $56(-21.13)$ & $50(-29.58)$ \\
\hline Extraversion & 37 & $63(70.27)$ & $63(70.27)$ & $57(54.05)$ & $53(43.24)$ \\
\hline Warmth & 29 & $58(100.00)$ & $50(72.41)$ & $53(82.76)$ & $49(68.96)$ \\
\hline Gregariousness & 37 & $60(62.16)$ & $50(35.13)$ & $46(24.32)$ & $46(24.32)$ \\
\hline Assertiveness & 34 & $54(58.82)$ & $58(70.59)$ & $46(35.29)$ & $54(58.82)$ \\
\hline Activity & 63 & $63(0.00)$ & $63(0.00)$ & $63(0.00)$ & $63(0.00)$ \\
\hline Excitement Seeking & 57 & $63(10.53)$ & $73(28.07)$ & $73(28.07)$ & $58(1.75)$ \\
\hline Positive Emotion & 31 & $54(74.19)$ & $51(64.52)$ & $51(64.52)$ & $40(29.03)$ \\
\hline Openness to Experience & 50 & $71(42.00)$ & $71(42.00)$ & $63(26.00)$ & $69(38.00)$ \\
\hline Fantasy & 40 & $68(70.00)$ & $66(65.00)$ & $63(57.50)$ & $60(50.00)$ \\
\hline Aesthetics & 40 & $57(42.50)$ & $63(57.50)$ & $56(40.00)$ & $60(50.00)$ \\
\hline Feelings & 49 & $58(18.37)$ & $58(18.37)$ & $60(22.45)$ & $69(40.82)$ \\
\hline Actions & 73 & $73(0.00)$ & $73(0.00)$ & $66(-9.59)$ & $73(0.00)$ \\
\hline Ideas & 47 & $54(14.89)$ & $54(14.89)$ & $50(6.38)$ & $54(14.89)$ \\
\hline Values & 66 & $71(7.57)$ & $63(-4.54)$ & $66(0.00)$ & $69(4.54)$ \\
\hline Agreeableness & 27 & $47(74.07)$ & $42(55.56)$ & $42(55.56)$ & 49 (81.48) \\
\hline Trust & 29 & $49(68.97)$ & $53(82.76)$ & $49(68.97)$ & $44(51.72)$ \\
\hline Straightforwardness & 32 & $42(31.25)$ & $42(31.25)$ & $37(15.63)$ & $40(25.00)$ \\
\hline Altruism & 27 & $56(107.41)$ & $34(25.93)$ & $47(74.07)$ & $53(96.3)$ \\
\hline Compliance & 37 & $50(35.14)$ & $47(27.03)$ & $34(8.11)$ & $54(45.95)$ \\
\hline Modesty & 51 & $51(0.00)$ & $51(0.00)$ & $50(-1.96)$ & $50(-1.96)$ \\
\hline Tender Mindedness & 42 & $40(-4.76)$ & $37(-11.90)$ & $49(16.67)$ & $53(26.19)$ \\
\hline Conscientiousness & 34 & $37(8.82)$ & $32(-5.88)$ & $40(17.65)$ & 40 (17.65) \\
\hline Competence & 37 & $42(13.51)$ & $37(0.00)$ & $40(8.11)$ & $42(13.51)$ \\
\hline Order & 27 & $27(0.00)$ & $27(0.00)$ & $29(7.41)$ & $29(7.41)$ \\
\hline Dutifulness & 34 & 40 (17.65) & $37(8.82)$ & $37(8.82)$ & $37(8.829$ \\
\hline Achievement Striving & 60 & $37(-38.33)$ & $46(-23.33)$ & $50(-16.67)$ & $49(-18.33)$ \\
\hline Self-Discipline & 40 & $51(27.50)$ & $50(25.00)$ & $50(25.00)$ & $54(35.00)$ \\
\hline Deliberation & 31 & $31(0.00)$ & $27(-12.90)$ & $40(29.03)$ & $42(35.48)$ \\
\hline
\end{tabular}

Note: \%PCP: Percentage of change from pretest; MFU: Month Follow-up.

Score interpretation: <36: very low; 36-45: low; 46-55: average; 56-65: high; > 65 very high. 
Table 5. Advantages and disadvantages of the videoconferencing treatment format according to patient and therapist

\begin{tabular}{|c|c|c|}
\hline & Advantages & Disadvantages \\
\hline Patient & $\begin{array}{l}\text { - Greater flexibility ("the treatment could be delivered from anywhere } \\
\text { in the world"). } \\
\text { - The use of email ("I felt that the therapy was more consistent over } \\
\text { time"). } \\
\text { - Convenience ("It is very comfortable doing the therapy at home"). } \\
\text { - Time saving ("given my work situation, living in China and with a big } \\
\text { work load, it is a major advantage to be able to attend therapy from } \\
\text { home"). }\end{array}$ & \\
\hline Therapist & $\begin{array}{l}\text { - No differences in the communication aspects and therapeutic alli- } \\
\text { ance compared with traditional therapy. } \\
\text { - High degree of presence at the meetings. } \\
\text { - Closer monitoring of the case ("due to the between-session work } \\
\text { that was sent by email"). } \\
\text { - Greater punctuality ("the patients do not have to travel, so they are } \\
\text { more likely to be on time"). }\end{array}$ & $\begin{array}{l}\text { - Increase of work ("the therapy format requires consult- } \\
\text { ing the email more frequently, preparing written materi- } \\
\text { al, and responding to the patient within the agreed } \\
\text { time"). } \\
\text { - Requires a more detailed account of the therapeutic } \\
\text { format (i.e., confidentiality or fees), and informal aspects } \\
\text { (i.e., where to connect or under what conditions). }\end{array}$ \\
\hline
\end{tabular}

\section{Conclusions}

The MCBT applied by videoconference was effective in reducing aggressive episodes; it had a positive impact on reduction of negative affect not only in clinical measures but also reflected in personality instability (Neuroticism). The treatment was also effective in increasing the experience of positive emotions both in clinical measures and in the personality profile (Extraversion and Openness). The results were maintained at the 18-month follow-up.

The analysis of the evolution of the personality facets showed high scores in impulsiveness, activity, and excitement seeking. Impulsiveness refers to the inability to control outbursts. Desires are perceived so intensely that the individual cannot resist them. High impulsivity scores are related to low tolerance frustration. A high activity score is considered indicative of speed and energy, the subject feels the need to always be busy. Finally, high excitement-seeking scores indicate a craving for excitement and stimulation. As can be observed, after treatment as well as in the follow-up, the patient maintains high scores on these personality facets. These results show, on the one hand, that the psychological intervention did not reduce these personality facet scores. Despite this, the patient currently shows no aggressive or dysregulation symptoms. Maybe more time is needed to reduce the scores of these personality facets. It can also be argued that positive changes in other personality dimensionssuch as Neuroticism, Extraversion, or Agreeableness- or personality facets - such as anxiety, angry hostility, assertiveness, or positive emotion-have had a sufficient and positive impact on emotion regulation processes and, despite high scores on these facets, the patient can adaptively cope with his daily stressors.

On the other hand, despite the fact that the Extraversion factor reflects the experience of positive emotions, if combined with impulsivity, it may lead to the emergence of dysregulation episodes (i.e., hypomania or mania). As some studies have shown, IED appears to be closely related to bipolar disorder (i.e., Kessler et al., 2006). This result suggests that it is necessary to conduct further research to determine whether more treatment sessions or more specific therapeutic tools to work on impulsiveness are needed, or whether it may be necessary to prescribe pharmacological treatment to reduce impulsiveness in these patients (McElroy, 1999).

The MCBT program we designed for this study was similar to the one used by McCloskey et al. (2008) although we included a third therapeutic component based on the promotion of positive emotions (Vázquez et al., 2006). Additionally, our program included 17 therapy sessions instead of 12 and it was applied by videoconference. As in McCloskey et al.'s study, our results support the efficacy of MCBT in the treatment of a case of IED with an 18-month follow-up.

The patient reported that the most important therapeutic tool for his improvement was everything that he learned about emotions (functionality of emotions, emotion components, etc.) and he highlighted the positive impact the treatment had in all areas of his life.

As shown in Table 5, the advantages of this treatment modality outweighed the disadvantages both for the patient and the therapist. These results are in line with those obtained by other authors (Simpson, 2009; Yuen et al., 2013). As other studies have shown, there is enough scientific evidence supporting the incorporation of the Internet as a useful clinical tool and showing that its low use is not justified (Soto-Pérez et al., 2010).With regard to the technical problems, some of them are unavoidable but, as Yuen et al. (2012) recommends, proper training of therapist and patient in the correct usage of the computer application and equipment could be a key to reduce some of them.

The limitations of the case study we present are related to the unstructured diagnostic interview used; also, a specific questionnaire to assess impulsive behavior (i.e. Impulsive Behavior Scale; Whiteside, \& Lynam, 2001) or cognitive control (i. e. Intentional Control Scale, Tortella-Feliu, et al., 2013) should have been included. It should be borne in mind that the patient is a high sociocultural level businessman accustomed to using technology tools like the comput- 
er, Internet and the Skype system, although he had never used them for this purpose.

Greater efforts are needed to disseminate the results of videoconferencing therapy, with emphasis on the type of condition being treated, assessment methods, patient characteristics, treatment design, efficacy, and satisfaction achieved. Scientific dissemination of the results of these investigations will help to overcome the prejudices that still affect a large number of professionals in the health sciences.

\section{References}

American Psychiatric Association (2013). Diagnostic and statistical manual of mental disorders ( $5^{\text {th }}$ ed.). Arlington, VA: Author.

American Psychiatric Association (2000). Diagnostic and statistical manual of mental disorders (4th ed., text rev.). Washington, DC: Author.

Anderson, G., Bergstrom, J., Hollandare, F., Carlbring, P., Kaldo, V., \& Ekselius, L. (2005). Internet-based self-help for depression: Randomized controlled trial. British Journal of Psychiatry, 187, 456-461. doi: 10.1192/bjp.187.5.456

Anderson, G., Carlbring, P., Holmstrom, A., Sparthan, E., Furmark, T., Nilsson-Ihrfelt, E., ... Ekselius, L. (2006). Internet-based self-help with therapist feedback and in vivo group exposure for social phobia: a randomized controlled trial. Journal of Consulting and Clinical Psychology, 74, 677-686. doi: 10.1037/0022-006X.74.4.677

Beck, A. T., Steer, R. A., \& Brown, G.K (1996). Manual for the Beck Depression Inventory-II. San Antonio, TX: Psychological Corporation.

Blankenship, K. (2008). Intermittent explosive disorder. Psychiatry Board Review Manual, 11, 1-8.

Botella, C., Osma, J., García-Palacios, A., Quero, S., \& Baños, R. M. (2004). Treatment of flying phobia using virtual reality: Data from a year follow-up using a multiple baseline design. Clinical Psychology and Psychotherapy, 11, 311-323. doi: 10.1002/cpp.404

Botella, C., Osma, J., García-Palacios, A., V. Guillén, \& Baños, R. (2008). Treatment of Complicated Grief Using Virtual Reality: A Case Report. Death Studies, 32, 674-692. doi: 10.1080/07481180802231319.

Coccaro, E. F. (2012). Intermittent explosive disorder as a disorder of impulsive aggression for DSM-5. American Journal of Psychiatry, 169, $577-$ 588. doi: 10.1176/appi.ajp.2012.11081259

Cordero, A., Pamos, A., \& Seisdedos, N. (1999). NEO PI-R Manual. Adaptación Española. Madrid: TEA Ediciones.

Costa, P., \& McCrae, R. (1992). NEO Personality Inventory Revised (NEO-PIR). Professional manual. Odessa, FL: Psychological Assessment Resources.

Del Vecchio, T., \& O’Leary, K. D. (2004). Effectiveness of anger treatments for specific anger problems: A meta-analytic review. Clinical Psychology Review, 24, 15-34. doi: 10.1016/j.cpr.2003.09.006

Goetter, E. M., Herbert, J. D., Forman, E. M., Yuen, E. K., \& Thomas, J. G. (2014). An open trial of videoconference-mediated exposure and ritual prevention for obsessive-compulsive disorder. Journal of Anxiety Disorders, 28, 460-462. doi: 10.1016/j.janxdis.2014.05.004

Guillén-Riquelme, A., \& Buela-Casal, G. (2011). Psychometric update and differential item functioning in the State Trait Anxiety Inventory (STAI). Psicothema, 23(3), 510-515.

Kessler, R. C., Coccaro, E. F., Fava, M., Jaeger, S., Jin, R., \& Walters, E. (2006). The prevalence and correlates of DSM-IV intermittent explosive disorder in the National Comorbidity Survey replication. Archives of General Psychiatry, 63, 669-678. doi: 10.1001/archpsyc.63.6.669

Knaevelsrud, C., \& Maercker, A. (2007). Internet-based treatment for PTSD reduces distress and facilitates development of a strong therapeutic alliance: A randomized controlled clinical trial. BMC Psychiatry, 7, 13. doi: 10.1186/1471-244X-7-13

Linehan, M. M. (1993). Skills training manual for treating borderline personality disorder. New York: Guilford Press.

Marco, J. H., Perpiñá, C., \& Botella, C. (2014). Tratamiento de la imagen corporal en los trastornos alimentarios y cambio clínicamente significa-
Note.- Financed by Gobierno de Aragón (Dpt. Industria e Innovación), European Social Fund and CREOS, centro de psicoterapia y formación.

Acknowledgments.- I would like to thank the participant of this study who gave his permission for this publication and also the psychologist of CREOS, centro de psicoterapia y formación for his commitment to clinical intervention and research.

tivo. Anales de Psicología, 30, 422-430. doi: 10.6018/analesps.30.2.151291.

McCloskey, M. S., Noblett, K. L., Deffenbacher, J. L., Gollan, J. K., \& Coccaro, E. F. (2008). Cognitive-behavioral therapy for intermittent explosive disorder: A pilot randomized clinical trial. Journal of Consulting and Clinical Psychology, 76, 876-886. doi: 10.1037/0022-006X.76.5.876

McElroy, S. L. (1999). Recognition and treatment of DSM-IV intermittent explosive disorder. Journal of Clinical Psycbiatry, 60 (15), 15-6.

Olvera, R. L. (2002). Intermittent explosive disorder: Epidemiology, diagnosis and management. CNS Drugs, 16, 517-526. doi: 10.2165/00023210-200216080-00002

Peñate, W. (2012). About the effectiveness of telehealth procedures in psychological treatments. International Journal of Clinical and Health Psychology, 12(3), 475-487.

Peterson, R. A., \& Reiss, S. (1993). Anxiety Sensitivity Index Revised test manual. Worthington, OH: IDS Publishing Corporation.

Proudfoot, J., Goldberg, D., Mann, A., Everitt, B., Marks, I., \& Gray, J. (2003). Computerized, interactive, multimedia cognitive-behavioral program for anxiety and depression in general practice. Psychological Medicine, 33, 217-227.

Proudfoot, J., Parker, G., Benoit, M., Manicavasagar, V., \& Smith, M. (2007). Helping patients adjust to the diagnosis of bipolar disorder: The role of an online psychoeducation program. Australian and New Zeland Journal of Psychiatry, 41, A498.

Reiss, S., Peterson, R. A., Gursky, D. M., \& McNally, R. J. (1986). Anxiety sensitivity, anxiety frequency, and prediction of fearfulness. Behaviour Research and Therapy, 24, 1-8. doi: 10.1016/0005-7967(86)90143-9

Roberts, R. E., Atkinson, C. C., \& Mendias, R. M. (1984). Assessing the Client Satisfaction Questionnaire in English and Spanish. Hispanic Journal of Behavioral Sciences, 6(4), 385-95. doi: 10.1177/07399863840064004

Rosenberg, M. (1989). Society and the adolescent self-image. Revised edition. Middletown, CT: Wesleyan University Press.

Sandín, B., Chorot, P., Lostao, L., Joiner, T. E., Santed, M. A., \& Valiente, R. M. (1999). The PANAS Scales of Positive and Negative Affect: Validation and cross-cultural factorial convergence. Psicothema, 1, 39-51.

Sandín, B., Chorot, P., \& McNally, R. J. (2001). Validation of the Spanish version of the Anxiety Sensitivity Index in a clinical sample. Behaviour Research and Therapy, 34, 283-290. doi: 10.1016/0005-7967 (95)00074-7

Sanz, J., Navarro, M. E., \& Vázquez, C. (2003). Spanish adaptation of the Beck Depression Inventory-II (BDI-II): 1. Psychometric properties in university students. Análisis y Modificación de Conducta, 29, 239-288.

Simpson, S. (2009). Psychotherapy via videoconferencing: A review. British Journal of Guidance and Counseling, 37(3), 271-286. doi: 10.1080/03069880902957007

Simpson, S. G. \& Reid, C. L. (2014). Therapeutic alliance in videoconferencing psychotherapy: A review. Australian Journal of Rural Health, 22, 280-299. doi: 10.1111/ajr.12149

Soto-Pérez, F., Franco, M., Monardes, C., \& Jiménez, F. (2010). Internet and clinical psychology: A cybertherapies review. Revista de Psicopatología y Psicología Clínica, 15, 19-37.

Spielberger, C. D., Gorsuch, R. L., \& Lushene, R. E. (1970). Manual for the State-Trait Anxiety Inventory. Palo Alto, CA: Consulting Psychologists Press. 
Spittaels, H., \& De Bourdeaudhuij, I. (2006). Implementation of an online tailored physical activity intervention for adults in Belgium. Health Promotion International, 221, 311-319. doi: 10.1093/heapro/dal030

Tortella-Feliu, M., Ibáñez, I., García de la Banda, G., Balle, M., AguayoSiquier, B., Morillas-Romero, A., \& Llabrés, J. (2013). La Escala de Control Intencional para adultos: Propiedades psicométricas de la versión catalana y sus relaciones con la regulación emocional cognitiva. Anales de Psicología, 29(3), 953-964. doi: 10.6018/analesps.29.3.135111

Vázquez, C., Hervás, G, \& Ho, S. (2006). Clinical interventions based in positive psychology: Basis and applications. Psicología Conductual, 14, 401-432.

Vázquez, J. A., Jiménez, R., \& Vázquez, R. (2004). The Rosenberg Selfesteem Scale. Apuntes de Psicología, 22, 247-255.

Villa, H., Botella, C., García-Palacios, A., \& Osma, J. (2007). Virtual reality in the treatment of panic disorder with agoraphobia: A case study. Cognitive and Behavioral Practice, 14, 58-69. doi: 10.1016/j.cbpra.2006.01.008

Vogel, P. A., Solem, S., Hagen, K., Moen, E. M., Launes, G., Haland, A. T.,... Himle, J.A. (2014). A pilot randomized controlled trial of videoconference-assisted treatment for obsessive-compulsive disorder. Behavior Research and Therapy, 63, 162-168. doi: 10.1016/j.brat.2014.10.007
Walters, S. T., Wright, J. A., \& Shegog, R. (2006). A review of computer and internet-based interventions for smoking behaviour. Addictive Behaviors, 31, 264-277. doi: 10.1016/j.addbeh.2005.05.002

Watson, D., Clark, I. A., \& Tellegen, A. (1988). Development and validation of brief measures of positive and negative affect: The PANAS scales. Journal of Personality and Social Psychology, 54, 1063-1070. doi: 10.1037/0022-3514.54.6.1063

Whiteside, S. P., \& Lynam, D. R. (2001). The Five Factor Model and impulsivity: Using a structural model of personality to understand impulsivity. Personality and Individual Differences, 30(4), 669-689. doi: 10.1016/S0191-8869(00)00064-7

Yuen, E. K., Goetter, E. M., Herbert, J. D., \& Forman, E. M. (2012). Challenges and opportunities in internet-mediated telemental health. Professional Psychology: Research and Practice, 43(1), 1-8. doi: 10.1037/a0025524

Yuen, E. K., Herbert, J. D., Forman, E. M., Goetter, E. M., Juarascio, A. S. Rabin, S., ... Bouchard, S. (2013). Acceptance based behavior therapy for social anxiety disorder through videoconferencing. Journal of Anxiety Disorders, 27, 389-397. doi: 10.1016/j.janxdis.2013.03.002

(Article received: 01-11-2014; revised: 15-01-2015; accepted:09-04-2015) 